\title{
TECNOLOGIAS DE INFORMAÇÃO E COMUNICAÇÃO EM TRABALHOS DE CONCLUSÃO DE CURSO LATO SENSU: UMA POSITIVA PARCERIA
}

\author{
TECNOLOGÍAS DE INFORMACIÓN Y COMUNICACIÓN EN TRABAJOS DE \\ CONCLUSIÓN DE CURSO LATO SENSU: UNA COLABORACIÓN POSITIVA
}

\section{DIGITAL TECHNOLOGIES OF INFORMATION AND COMMUNICATION IN END OF COURSE PAPERS LATO SENSU}

\author{
Ivo José BOTH ${ }^{1}$ \\ Kátia Cristina Dambiski SOARES ${ }^{2}$ \\ Desiré Luciane Dominschek LIMA ${ }^{3}$ \\ Marcos Aurélio Silva SOARES ${ }^{4}$
}

RESUMO: Este trabalho objetiva demonstrar experiências de orientações e defesas de trabalhos de conclusão de curso do Centro Universitário Internacional Uninter, com o uso de tecnologias digitais de informação e comunicação. As 355 orientações dos trabalhos ocorreram de forma assíncrona e síncrona, enquanto as defesas realizaram-se de forma síncrona. Alguns dos autores consultados foram: Luckesi, Romanowski, Wachowicz, Saraiva. Os principais resultados decorrentes da forma assíncrona e síncrona das orientações e defesas dos trabalhos refletem-se na agilidade de ação, na flexibilidade de emprego do tempo e no comprometimento com a boa qualidade da maioria dos artigos científicos.

PALAVRAS-CHAVE: Orientação. Assíncrona e Síncrona. Comprometimento. Qualidade.

RESUMEN: Este trabajo tiene el objetivo de demostrar experiencias de orientaciones $y$ presentación de trabajos de conclusión de curso del Centro Universitario Internacional Uninter, con el uso de tecnologías digitales de información y comunicación. Las 355 orientaciones de los trabajos ocurrieron de forma asíncrona y síncrona, mientras las presentaciones se realizaron de forma síncrona. Algunos de los autores consultados fueron: Luckesi, Romanowski, Wachowicz, Saraiva. Los principales resultados derivados de la forma asíncrona y síncrona de las orientaciones $y$ presentaciones de los trabajos se reflejan en la agilidad de la acción, en la flexibilidad de empleo del tiempo y en el comprometimiento con la buena cualidad de la mayoría de los artículos científicos.

\footnotetext{
${ }^{1}$ Doutor em Educação na área de Política Educacional pela Universidade do Minho, Portugal. É membro da Academia de Letras dos Campos Gerais-Ponta Grossa-PR. Professor titular em cursos de graduação e de pós-graduação presenciais e a distância. Email: ivo.b@uninter.com

2 Doutora em Educação. Universidade Federal de Santa Catarina (UFSC) e Professora do Centro Universitário Internacional UNINTER. Email: katiadsoares@ hotmail.com.br

3 Doutoranda em Educação. Universidade Estadual de Campinas (Unicamp). Mestre em Educação. Universidade Federal do Paraná (UFPR) e Professora do Centro Universitário Internacional UNINTER.. Email: desire.d@uninter.com

4 Mestre em Educação e Trabalho. Universidade Federal do Paraná (UFPR) e Professor do Centro Universitário Internacional UNINTER. Email: soaresmarcos@ hotmail.com.br
} 
PALABRAS CLAVE: Orientación Asíncrona y Síncrona. Comprometimiento. Cualidad.

ABSTRACT: This paper aims to demonstrate experiences of orientations and of defenses of end of course papers from Centro Universitário Internacional Uninter, with the use of information and communication digital technologies. The 355 advising orientations happened in the asynchronous and synchronous form, while the defenses made use of the synchronous form. Some of the authors were consulted: Luckesi, Romanowski, Wachowicz, Saraiva. The main results of the asynchronous and synchronous ways of orientation and defense of the papers had reflected in the agility for action, in the flexibility on the use of time and in the commitment to the good quality of most of the scientific articles.

KEYWORDS: Orientation. Asynchronous and Synchronous. Commitment. Quality.

\section{Introdução}

As principais novas tecnologias que se apresentam no mercado demonstram bons resultados nos meios estudantis. Várias delas, como o computador, tablets, celulares, dependendo da habilidade técnica com que são utilizadas, facilitam a implementação de trabalhos de pesquisa e, em consequência, favorecem sensivelmente a aprendizagem.

Por si só, as tecnologias digitais de informação e comunicação pouco representam ao meio social, mas, na medida em que a sua relação ocorre de forma mediada com iniciativas educacionais, elas se tornam altamente úteis e proveitosas.

Para o trabalho ora em foco, a integração entre trabalho acadêmico e tecnologia surtiu efeitos de primeira grandeza, em que docente e discente usufruíram de benefícios acadêmicos tais que, não fosse a aliança estabelecida entre esta metodologia de trabalho posta em prática e o uso da tecnologia em questão, os resultados acadêmicos possivelmente não teriam sido tão positivos.

\section{Se presencial ou a distância a modalidade educacional, a tecnologia tende a favorecer a aprendizagem e o desempenho}

Um ponto importante a ser discutido quando se trata das possibilidades de enriquecimento da aprendizagem com o uso das novas tecnologias é a questão da avaliação educacional. Assim, ao abordar a questão da elaboração de Trabalhos de Conclusão de Curso no âmbito da graduação, merece destaque a compreensão de avaliação formativa. Nesta direção, da mesma forma como é abordada com a necessária 
profundidade a avaliação em seus aspectos formativos, de igual modo é tratada com a merecida atenção a avaliação somativa, sempre como fiel aliada da avaliação formativa.

De imediato percebe-se que academicamente as duas grandes colunas centrais de avaliação - formativa e somativa - não se manifestam entre si radicalmente antagônicas, ainda que pedagogicamente a primeira esteja merecendo maior receptividade e aceitação nos meios escolares.

Para recordar a função de uma e outra, retomamos os conceitos formulados por Romanowski e Wachowicz (2003, p.124-127), que definem a avaliação formativa como a que procura acompanhar o desempenho do aluno no decorrer do processo de aprender e a somativa a que é realizada no final desse processo e visa indicar os resultados obtidos para definir a continuidade dos estudos, isto é, se o aluno foi ou não aprovado.

A avaliação processual (formativa) cumpre função contínua no processo de aprendizagem, ao passo que a somativa intervém nele de forma pontual, numéricoestatisticamente. Esta modalidade, ainda que menos recomendada pedagogicamente nos meios escolares, não deixa de ter sua importância, principalmente quando o valor numérico, a média e o fator estatístico continuam sendo bastante valorizados nos meios educacionais oficiais.

Por isso mesmo, assume-se como pressuposto que tanto a avaliação formativa, quanto a avaliação somativa podem ser utilizadas nos processos educativos. E, na mesma direção, não importa se a implementação da educação ocorre na modalidade presencial ou na modalidade a distância, o objetivo a ser cumprido é o mesmo: o de propiciar aprendizagem e desempenho acadêmico de boa qualidade aos alunos.

Em termos de iniciativas de educação a distância $(\mathrm{EaD})$ o Brasil encontra-se bastante defasado em comparação com vários dos países europeus, além dos Estados Unidos e Canadá, ainda que de alguns anos para cá a EaD venha se consolidando em terras brasileiras as oportunidades de educação a distância por instituições de ensino superior país afora, de modo especial na dependência administrativa privada.

As diferenças maiores existentes entre as duas modalidades de educação residem na aplicação metodológica, na instrumentação tecnológica, no apoio bibliográfico, no sistema de avaliação e na prestação do trabalho de tutoria. No entanto, a qualidade da aprendizagem se equivale, quando cada modalidade é bem organizada e implementada no seu respectivo contexto e característica.

Se na educação presencial a relação entre professor e aluno se dá praticamente face a face, mas atingindo a um número reduzido de pessoas, na educação a distância 
essa relação acontece também com razoável empatia, no entanto, com o atingimento de um número infinitamente maior de alunos, simultaneamente, inclusive de comunidades remotas e carentes de recursos educacionais.

Possivelmente haja interesse em conhecer as diferenças práticas e pedagógicas entre educação presencial e a distância. Tal interesse é louvável, uma vez que ainda existe por um lado certa desconfiança com relação à validade e à qualidade do ensino ofertado na modalidade a distância e, por outro lado, perdura a descrença também referente à qualidade da educação presencial.

A desconfiança com relação à educação a distância deve-se muito em função de seu desconhecimento por grande parte da massa populacional, enquanto a descrença referente à educação presencial decorre principalmente de sua vagarosa e indecisa reação por melhores resultados educacionais.

Podem ser citadas ainda outras pequenas e relativas diferenças entre as duas modalidades de educação, a saber:

a) Educação presencial:

- flexibilidade de emprego de métodos e de metodologias de ensino de acordo com as necessidades escolares do dia-a-dia;

- possibilidade de negociação pontual de interesses acadêmicos com o professor;

- prática de relativa autonomia de estudo;

- capacidade de autodeterminação nem sempre compatível com as necessidades acadêmicas;

- alcance geográfico limitado, o que reduz possibilidades de realização de cursos em nível de graduação e de pós-graduação;

- disponibilidade de cursos de formação e qualificação em todas as áreas de conhecimento;

- atuação docente por vezes não compatível com algumas exigências acadêmicas, devido à insuficiência de profissionais qualificados para atendimento.

b) Educação a distância:

- métodos e metodologias de ensino elaborados especialmente para atenderem a essa modalidade de ensino;

- reduzida possibilidade de negociação entre aluno e professor em aula;

- elevada capacidade de autonomia de estudos pelo aluno;

- elevada capacidade de autodeterminação acadêmica; 
- ilimitado alcance geográfica desta modalidade de ensino;

- elevado nível de competência docente;

- diversidade de mecanismos de comunicação com os alunos diminuem sua dependência do professor;

- materiais didáticos elaborados de forma dialógica por especialistas, bem como disponibilidade de tecnologias avançadas favorecem a aprendizagem;

- fixação dos alunos em seu meio cultural e social.

As abordagens comparativas entre ensino presencial e a distância não podem ser tomadas invariavelmente ipsis litteris, uma vez que sua variação está diretamente relacionada tanto à capacidade de organização acadêmica de cada Instituição de ensino, como a características sócio-econômico-culturais locais e regionais.

Ambas as modalidades estão em condições de ofertar ensino de excelente qualidade. Além do mais, em termos legais, os diplomas dos formados pela via de educação a distância possuem o mesmo valor dos concluintes na modalidade presencial.

Segundo o Decreto da Presidência da República $n^{\circ}$ 5.622, de 19/12/2005, no artigo $5^{\circ}$, ao tratar do valor legal dos diplomas em nível nacional, assim se expressa: “Os diplomas e certificados de cursos e programas a distância, expedidos por instituições credenciadas e registrados na forma da lei, terão validade nacional".

Este artigo dirime as principais dúvidas que até aqui ainda estavam perdurando com relação à validade dos diplomas decorrentes de cursos de educação a distância e, por extensão, encoraja novas iniciativas de cursos nessa modalidade de ensino.

Cabe também dizer que, ainda que esteja presente no Brasil de maneira mais intensa desde a década de noventa, a educação a distância veio se firmar de vez como mais uma modalidade educacional, mas sem pretensão de tomar conta sozinha das atividades educativas. Assim, é importante destacar que países da Europa e da América do Norte nessa modalidade de ensino soma inúmeras décadas de experiências, sem fechar espaços para a educação presencial, o que vem ocorrendo em terras brasileiras.

A educação a distância tem seu foco voltado para onde quer que as necessidades educativas se manifestem, mas sem deixar de cumprir sua filosofia de atender aquelas populações onde a educação presencial tem dificuldades de se fazer presente.

Também é preciso considerar que, daqui por diante a educação presencial sofrerá céleres mudanças em seus métodos de oferta de ensino, pressionada 
principalmente pelo aumento da intensidade do uso de novas tecnologias bem sucedidas pela modalidade a distância.

\section{A complexidade da educação faz-se inteligível pela avaliação}

O bom senso representa ser uma das máximas em avaliação, de vez que cabe ao professor responsabilizar-se, não pelo aluno como pessoa, mas pelo conhecimento que oportuniza e pela reação e mudança comportamental que lhe provoca como ser social. $\mathrm{O}$ bom senso do professor também deve imperar, no sentido de que essa reação e mudança comportamental ocorrerem a seu tempo e em ritmo adequado.

A representação do aluno como "ser com os outros" faz dele um ser social, em que o conhecimento adquirido poderá facultar-lhe suficiente liberdade para anuir por decisão própria e autônoma, os caminhos pelos quais se conduzirá no meio social.

O binômio aprendizagem-avaliação permite ao aluno reconhecer o seu papel tanto na família quanto na sociedade, como ser cooperador, criativo, participativo e corresponsável pela gradual elevação da qualidade de vida.

Por certo, deve o ato de avaliar ser considerado sob quatro prismas intercomplementares:

- como processo de justiça para com o aluno;

- como ato de responsabilidade ante o desempenho do aluno;

- como diagnóstico da realidade, com estabelecimento de juízo de valor a partir de dados significativos;

- e como tomada de decisão para a solução de situações-problema.

A avaliação é um processo que consiste em fazer um julgamento comparativo entre o desempenho demonstrado e o resultado pretendido. Avaliação como processo sempre faz prevalecer a qualidade do desempenho sobre a quantidade de atividades realizadas pelo aluno ou por profissional de qualquer área.

Assim sendo, ênfase maior sempre cabe ser dada ao processo do que ao produto resultante da combinação ensino-aprendizagem. Por outro lado, cabe ao professor ter em consideração a valorização das possibilidades e das potencialidades do aluno em maior grau do que suas eventuais limitações. 
Tal fato torna-se necessário ressaltar, de vez que ainda persiste com certo grau de grandeza no meio acadêmico e no mercado de trabalho, em geral, tomar como ponto decisivo de julgamento eventuais limitações de variada ordem das pessoas, em detrimento de suas potencialidades, que, quando bem aquilatadas, conseguirão se sobrepor, muitas vezes, à presença de dificuldades por conta de necessidades especiais.

Se por um lado ainda persistem discrepâncias e tendências prejudiciais à avaliação, de outra parte também vão se encaminhado avanços seus, tanto com relação a aspectos teóricos quanto a práticos.

Tendo como uma de suas preocupações educacionais mais relevantes a descoberta e a valorização das potencialidades do aluno, torna-se mais fácil encarar um dos maiores desafios avaliativos do docente, que é o de saber o que é mais relevante perguntar, propor, descobrir ou recomendar ao aluno.

$\mathrm{O}$ ato de avaliar pode contribuir decisivamente para o estabelecimento de autoavaliação pelo professor que, por vezes, torna-se tão necessária quanto a heteroavaliação.

Um processo avaliativo possibilita representar ao professor e ao aluno, na mesma proporção, oportunidade ímpar de obtenção de elementos para reflexão sobre a prática pedagógica docente e sobre a construção da aprendizagem dos alunos.

Além de possibilitar a identificação do nível de desempenho, de rendimento e de produção do aluno ou de qualquer outro profissional, a avaliação ainda pode oportunizar a impressão de maior qualidade no relacionamento entre professor e aluno. Isso, porque o binômio aprendizagem-avaliação possui como escopo educação. E, somente conseguem dialogar e aproximar-se para uma salutar convivência, pessoas imbuídas de valores educacionais.

A avaliação se constitui em atribuição de valor. Ter valor. Ser válido. No entanto, a valoração que aí se estabelece não se reduz a formas numéricas, mas compreende ações de promoção de desenvolvimento construtivo sócio pessoal.

A avaliação significa modelo moderno, subjetivo, em que a medida não se restringe a um valor estático, "frio", mas age como instrumento pedagógico real da experiência humana. $\mathrm{O}$ acompanhamento do aluno se desenvolve de forma construtiva. O educando tem seu desenvolvimento garantido através da aprendizagem. E os fatores que se impõe em tal aprendizagem são principalmente os de cunho social.

Não é pretensão dizer que a verificação concebe a aprendizagem apenas com olhos quantitativos, no entanto o hiato qualitativo existente entre ela e a avaliação é 
grande por demais. A avaliação se constitui em ação construtiva, de acompanhamento do educando como ser em constante evolução tanto em nível de aquisição de conhecimentos como em termos de formação pessoal.

Luckesi (1988, p. 32) entende "avaliação como um juízo de qualidade sobre dados relevantes, tendo em vista uma tomada de decisão”. O juízo parte de um padrão de qualidade, em que são abordados somente dados relevantes para tomada de decisão.

Numa avaliação não são aceitos dados que não oportunizem real juízo de qualidade. Os dados relevantes são a expressão da realidade, sendo omitidos dados externos, irrelevantes, sociais...

Mediante uma avaliação não se entende como aprovado um aluno só por se enquadrar numa média como aprovado ou um aluno só por se enquadrar numa média numérica dentro dos padrões oficialmente estabelecidos, mas sim, por ter concordado plenamente em participar do processo de aprendizagem e porque alcançou, ao menos, conhecimentos mínimos necessários de forma crítico-construtiva.

A ação dinâmica e construtiva aguardada da avaliação, permite encarar o aluno como um ser que se desenvolve de forma global. A mudança comportamental se manifesta tanto em nível de aquisição de conhecimentos de forma consciente como em termos de relacionamento social e de aceitação de seu desenvolvimento pessoal.

Numa avaliação também fica subentendido o nível de relacionamento existente entre professor e aluno, o crescer-juntos em permanente evolução acompanhada. Para Ávila (1972, p. 77-78), a avaliação "é a ação de apreciar em seu justo valor um ser, situação, atitude ou sentimento, considerando de modo objetivo os fatores ou elementos de que são constituídos".

Considerada dessa forma, foge a avaliação do sentido com que é comumente encarada, quando é confundida com mera verificação, constatação, aferição. Para o autor (ibid), ainda, "a avaliação é a base consciente para estabelecimento das condições necessárias à vida e ao progresso humano, tanto individual como social”. Assim concebida, a avaliação efetivamente se enquadra numa atribuição de qualidade, sobre dados relevantes, para a tomada de decisão.

Para Saraiva (2005, p.32), "se a avaliação permear todo o processo de ensinoaprendizagem e se for entendida em todas as suas dimensões- avaliação do aluno, do professor, da escola-, possibilitará ajustes que contribuirão para que a tarefa educativa seja coroada de sucesso". 
Também diz a autora que "avaliar a aprendizagem do aluno significa, concomitantemente, avaliar o ensino oferecido. Se não houver a aprendizagem esperada estamos diante de uma certeza - o ensino não cumpriu sua finalidade - a de fazer aprender".

Certamente, chegam a ser antagônicas as diferenças que se estabelecem entre avaliação e verificação. Como foi enfatizado anteriormente, enquanto a avaliação se constitui em processo dinâmico, construtivo e de acompanhamento crescente do aluno ao longo de todo o processo, a verificação é um ato estático, de constatação, de medida, de aferição, não permitindo a necessária visão de educando como um ser que necessita desenvolver-se em sua globalidade.

A verificação é uma medida, ainda que não recomendável quando do trato de questões de ensino-aprendizagem dos alunos. Representa ela um desvio de conduta da filosofia de avaliação, apresentando-se como experiência autoritária que vem perpassando a sociedade através dos tempos, cuja fonte de inspiração possivelmente tenha sido a burguesia européia, que mais tarde também foi se estabelecendo no Brasil.

Para Luckesi (1992), avalia-se mais o que o aluno não sabe, do que o que ele possa estar sabendo. Tal atitude do professor insere-se perfeitamente na filosofia comportamental autoritária da verificação. Esse comportamento faz-se bastante presente tanto em sala de aula quanto na família, como nas autoridades governamentais. São instâncias que se encontram no modelo metafísico, objetivo, frontalmente opostas ao pensamento moderno, subjetivo.

Ainda se debate a sociedade grandemente entre o modelo metafísico e o moderno. Nesse meio, a verificação se comporta como instrumento de controle, em que professores aliados seus preferem expor o aluno a terem que se expor. Por outro, a verificação se caracteriza por ato de administração do poder na ação pedagógica, quando o aluno é examinado muitas vezes justamente a partir do que ele menos sabe.

A verificação não elabora juízo preferencialmente a partir de dados de maior relevância para a tomada de decisões. O juízo é estabelecido sobremaneira com base em dados quantitativos. Dados externos, não relevantes, por vezes decidem o valor símbolo numérico ou conceito - a ser atribuído ao aluno.

Enquanto a avaliação se baseia em dados qualitativos, de crescimento, de mudança comportamental do educando, a verificação busca acobertar-se em dados quantitativos, cujas médias são alcançadas a partir da aplicação de operações 
matemáticas. A verificação torna-se bem menos trabalhosa que a avaliação, justamente devido à sua precípua função constatadora, estática.

Cada professor segue, em grande dose, critérios próprios com relação à avaliação, todavia seu empenho pelo atingimento por parte do aluno, ao menos dos conteúdos-conhecimentos-mínimos exigidos no processo de ensino-aprendizagem, deve se constituir uma máxima universal. Por certo, a avaliação é exigente em seus critérios de promoção, no entanto procura ela empenhar-se ao máximo junto ao processo de ensino-aprendizagem pela progressão do estudante que tenha demonstrado real desenvolvimento de qualidade face aos conhecimentos adquiridos ao longo do processo.

Sendo dinâmica, contínua e construtiva, a avaliação não se dá bem com a obediência à calendários oficiais que demarcam a sua implementação ao longo do processo de ensino-aprendizagem. No entanto, ela também não opõe à conversão da aprendizagem qualitativa em conceitos ou notas, ao final do processo, que representem a aprovação ou a reprovação do aluno ou para outros fins.

Notas e conceitos, portanto, são aceitos na avaliação, contando que não interrompam a dinamicidade do processo de aprendizagem. Os aspectos quantitativos jamais podem sobrepor-se aos qualitativos, sob pena de a aprendizagem perder seu sentido crítico-construtivo.

Entende-se que num processo de avaliação, com a divisão do senso de responsabilidades, de justiça e de equilíbrio entre professor e aluno, podem ser perfeitamente dispensados procedimentos no processo de aprendizagem, como:

- fórmulas matemáticas para cálculo de médias, que indiquem notas ou conceitos;

- controle de frequência dos alunos; e

- elaboração de calendário prévio para avaliações intermediárias.

Fórmulas matemáticas para cálculo de médias com fins de aferição de notas ou conceitos, por exemplo, são exigências administrativamente comuns em instituições de ensino, como forma de socorrer "avaliadores" que sentem dificuldades na implementação de um genuíno processo de avaliação.

Infelizmente, a verificação permite que algumas injustiças persistam na relação professor-aluno. Primeiro, já dito anteriormente, quando o professor tem tendência de avaliar mais o que o aluno não sabe, ao invés de valorizar em igual intensidade também os aspectos da aprendizagem que realmente domina. Por outro, ainda perdura um comportamento de pouca humildade: quando o aluno demonstra bom domínio de conhecimentos, é porque o professor é bom; quando pouco sabe, a responsabilidade 
recai principalmente sobre o aluno. Para Leite (1988, p. 92), "os resultados negativos da avaliação são utilizados principalmente contra os alunos".

\section{Tecnologias digitais de informação e comunicação em trabalho acadêmico: resultados de uma experiência bem sucedida}

A implementação de curso de "Formação de docentes e orientadores acadêmicos em educação a distância (EaD)”, em nível de pós-graduação lato sensu, na modalidade a distância, com abrangência nacional em terras brasileiras, por si só representaria um grande desafio, levando-se em conta ser a $\mathrm{EaD}$, por ora, ainda considerada uma experiência educacional recente no Brasil, quando comparada com países de vanguarda nessa modalidade.

O curso em questão foi de iniciativa da então Faculdade Internacional de Curitiba (FACINTER) atual Centro Universitário Internacional UNINTER, em que a exigência para trabalho de conclusão de curso foi a elaboração individual de artigo de cunho científico, com base em resultados de investigação científica.

Para este estudo foram elencados 355 artigos aprovados, sendo que em torno de $80 \%$ deles foram submetidos à defesa pelos seus autores durante o ano de 2011, oriundos de diferentes localidades do território nacional.

As orientações dos trabalhos ocorreram de forma assíncrona, por meio de Ambiente Virtual de Aprendizagem (AVA), e síncrona mediante a utilização de Chat entre orientador e orientando. No AVA os alunos postaram e submeteram primeiramente as suas propostas de pesquisa ao crivo de orientação e, na sequência, os respectivos artigos, elaborados com base em resultados dessas investigações, eram igualmente postos à análise do seu orientador nessa mesma plataforma tecnológica, tantas vezes quantas fossem necessárias, até a aprovação dos textos finais.

O Chat foi utilizado como uma tecnologia síncrona de agir, resultando em comunicação complementar entre orientador e orientando, principalmente em função de orientandos que necessitavam de orientações de forma mais ampla e profunda que os demais estudantes.

Tanto os trabalhos de orientação quanto os de defesa obedeceram a calendário específico e as defesas dos trabalhos de conclusão de curso, na forma de artigos, por sua vez, transcorreram de duas formas: 
a) síncrona, via internet, na sua grande maioria, com são e imagem simultâneos para o orientador em estúdio e para os orientandos em diferentes Polos de Apoio Presencial-PAP país afora;

b) e de forma presencial para orientandos da região metropolitana de Curitiba.

Percebe-se que o uso de tecnologia digital de informação e comunicação foi fundamental para que o curso de "formação de docentes e orientadores acadêmicos em educação a distância (EaD)" fosse levado a bom termo, incluindo as atividades de investigação, de orientação na elaboração dos artigos como trabalhos de conclusão de curso e, por fim, o cumprimento de defesa dos respectivos trabalhos perante banca examinadora.

Segundo Purificação e Brito (2008, p. 23), “assumimos, então, educação e tecnologia como ferramentas que podem proporcionar ao sujeito a construção de conhecimento, preparando-o para saber criar artefatos tecnológicos, operacionalizá-los e desenvolvê-los".

As tecnologias digitais de informação e comunicação, quando bem direcionadas e aplicadas adequadamente por pessoas que demonstram pleno domínio técnico sobre elas, podem cumprir apoio promissor e positivamente diferenciado ao desenvolvimento educacional em todos os níveis escolares, como:

- no desenvolvimento de eventos educacionais: eventos constituem iniciativas positivas de benefício social, genericamente, e educacional, em sua singularidade, podendo contribuir largamente no aprofundamento de temas de interesse público;

- no desenvolvimento de aulas: tecnologias digitais de informação e comunicação contribuem ampla e decisivamente na melhoria de aprendizagem e na elaboração de conhecimentos política e pedagogicamente pertinentes;

- na orientação e defesa de trabalhos escolares: distância e procura por referenciais conteudísticos para a elaboração, a orientação e a defesa de ideias na forma de produção científica não mais constituem barreiras nem físicas, nem de apoio humano;

- no desenvolvimento de atividades de investigação: pesquisa científica é o meio mais confiável para a promoção de novos conhecimentos e mesmo para a atualização de conhecimentos já existentes; 
- no desenvolvimento de atividades e de estudos de forma individual ou coletiva: o estudo individual que dê consistência para conhecimentos em uso constitui iniciativa pedagógica salutar, mas, quando tais estudos emanam de acréscimo tecnológico e de empenho de recursos humanos de variada formação, os resultados acadêmicos por certo se configuram bastante consequentes;

- democratizar acesso à educação de igual modo para pessoas de diferentes condições físicas e de saúde em todos os níveis sociais.

Martins (2010, p. 16) ainda reforça a afirmação anterior, dizendo que

o professor que associa as tecnologias de informação aos métodos ativos de aprendizagem desenvolve habilidades relacionadas ao domínio da tecnologia e articula esse domínio com a prática pedagógica e com as teorias educacionais, possibilitando ao aluno reflexão sobre a sua prática, ampliando as potencialidades pedagógicas das tecnologias de informação.

A autora permite entender que o domínio técnico por si só não basta ao educador, sob pena de esmorecer no vazio. No entanto, quando o educador consegue associar de forma consequente a tecnologia à ação pedagógica, os resultados educacionais possivelmente serão bastante ricos.

Com o aumento de potencialidades pedagógicas mediante o uso de tecnologias digitais de informação e comunicação, por certo surgirão benefícios que favorecem o ser humano em diversas condições vivenciais, a saber:

- facilitação e melhoria da aprendizagem; é a aprendizagem um dos principais pilares para que o conhecimento aconteça como apoio ao aumento e à melhoria de desempenho pessoal, social e profissional do ser humano.

- possibilidades de elaboração de novos e renovados conhecimentos; o surgimento de novos conhecimentos é imprescindível para que a formação escolar se enriqueça e se afirme, no entanto, a nova "roupagem" a ser dada a conhecimentos já existentes também se torna passo pedagógico importante no meio escolar.

- aumento e melhoria de desempenho físico, psicológico e mental; na medida em que o ser humano for se descobrindo em suas potencialidades por vezes ainda desconhecidas, o seu desenvolvimento e desempenho global vão tomando concretude. 
- melhoria de condições de vida; potencialidades pedagógicas, quando reconhecidas pelo ser humano, auxiliam na mediação para o desenvolvimento global da pessoa, com caminho aberto para a melhoria de qualidade de vida pessoal e social.

- estabelecimento de atuação interativa entre informações, recursos tecnológicos e pessoas.

As potencialidades pedagógicas, amparadas e mediadas por tecnologias digitais de informação e comunicação, ajudam a dar ponto de equilíbrio ao ser humano em sua realização pessoal e social.

Os principais resultados decorrentes da forma assíncrona e síncrona de orientação e de defesa dos trabalhos refletem-se na agilidade de ação, na flexibilidade de emprego do tempo e no comprometimento com a boa qualidade dos artigos científicos.

A agilidade de ação está diretamente relacionada ao "encurtamento" das distâncias entre orientador e orientando mediante o uso de tecnologias digitais de informação e comunicação, considerando o tamanho praticamente continental do espaço geográfico brasileiro, em que as condições de acesso são díspares, indo de precárias regiões ribeirinhas a grandes centros urbanos, e o elevado número de trabalhos de conclusão de curso: 355 .

Mesmo que as distâncias físicas entre a sede permanente das bancas examinadoras dos trabalhos na cidade de Curitiba e a localização dos alunos para a defesa dos seus artigos nos respectivos Polos de Apoio Presencial-PAP tenham sido, na sua grande maioria, imensas, mesmo assim, as providências tomadas para as defesas na forma síncrona demandaram, em média, menos tempo do que as defesas presenciais. Também é importante dizer que as bancas examinadoras dos trabalhos eram compostas por dois (2) docentes doutores.

Ainda levando em conta o vasto espaço físico que separava orientador em sua sede na cidade de Curitiba-PR e os autores dos trabalhos de conclusão de curso espalhados país afora, mesmo assim a flexibilidade no emprego do tempo foi fator bastante favorável no reordenamento rápido e eficaz dos desvios de conduta que eventualmente se manifestavam com relação ao cumprimento das atividades programadas. Senão, vejamos: ocorreram em diversas oportunidades falhas técnicas em equipamentos eletrônicos tanto na sede localizada em Curitiba-PR quanto em Polos de Apoio Presencial-PAP, país afora, provocando interrupção na comunicação entre 
orientador e orientando, ou em momentos de defesa de trabalhos ou na comunicação via chat entre os interessados.

Possivelmente o ponto mais alto verificado no contexto das atividades de orientação e de defesa dos trabalhos tenha sido o comprometimento dos orientandos com o desenvolvimento das respectivas pesquisas e com a consequente elaboração dos artigos de cunho científico.

O comprometimento dos orientandos com relação ao seu bom desempenho na parte tecnológica e na parte científica de produção dos textos vem a confirmar que tecnologia e espírito científico podem conviver em perene harmonia intercomplementar.

Veja-se que aqueles poucos orientandos que não demonstravam pleno domínio da tecnologia digital de informação e comunicação, souberam superar essa deficiência, aprendendo em serviço.

Além do mais, mesmo que a elaboração de textos em nível de pós-graduação lato sensu (especialização) não constituísse prática usual e corrente para todos os orientandos, grande parte dos artigos por eles elaborados está apto a ser selecionado para fins de publicação em periódicos de reconhecimento nacional e internacional.

Sabe-se que, a par de tantos pontos positivos enumerados com relação ao bom desempenho da maioria dos orientandos, um que outro aspecto de menor positividade também deve ser apontado, com propósito, inclusive, preventivo de sofrerem ajustes em outros eventos dessa dimensão que venham a ser programados.

\section{Considerações Finais}

Pode-se vislumbrar boas perspectivas no emprego de tecnologias digitais de informação e de comunicação, para o bem da educação brasileira em futuro que não está tão distante, a contar das percepções positivas recolhidas durante o cumprimento das funções tanto de orientação na consecução dos trabalhos de investigação e de elaboração dos artigos, quanto na participação das bancas das respectivas defesas dos alunos dos seus textos elaborados como requisitos de conclusão do curso de "formação de docentes e de orientadores acadêmicos em educação a distância (EaD)", com abrangência nacional. 
A defesa de trabalhos com o uso de tecnologias de informação e comunicação não encontra barreiras nem de espaço, nem de tempo, bastando que o seu emprego se faça com adequado acerto tecnológico.

\section{REFERÊNCIAS}

ÁVILA, Padre Fernando Bastos de. Pequena Enciclopédia de Moral e Civismo. Ministério da Educação e Cultura. FENAME. Rio de Janeiro. 1972.

BRASIL. MEC. Portaria Normativa n. 02/2007. Regulação e avaliação da educação superior na modalidade a distância.

BRITO, G. da S. e Purificação, I. da. (2008). Educação e novas tecnologias: um repensar. 2. ed. rev. atual. e ampl. Curitiba: IBPEX.

FRANCA, Padre Leonel. O Método Pedagógico dos Jesuítas. Rio de Janeiro. Agir, 1952.

LEITE, Sérgio A. da Silva. O Ensino de Primeiro Grau: da Crítica a Propostas Alternativas. In: Brasil. Secretaria da Educação Superior. Educação Superior e Educação Básica: coletânea de textos. Brasília. MEC: Uberlândia, UFU. 1988.

LUCKESI, Cipriano Carlos. Avaliação do aluno: a favor ou contra a democratização do ensino? Brasília. V Conferência Brasileira de Educação. 2-5 ago. 1988.

LUCKESI, Cipriano Carlos. Apontamentos de diálogo. Curitiba, ago. 1992.

MARTINS, Onilza B. (2011). Formação do orientador acadêmico (tutor): teoria e prática. Disponível em:

<http://ava.grupouninter.com.br/claroline176/claroline/learnPath/navigation/viewer.php >. Acesso em: 07 nov. 2011.

ROMANOWSKI, Joana Paulin; WACHOWICZ, Lílian Anna. Avaliação formativa na educação superior: que resistências manifestam os professores e os alunos? In: ANASTASIOU, Léa das Graças Camargos; ALVES, Leonir Pessate (Orgs). Processos de ensinagem na universidade: pressupostos para as estratégias de trabalho em aula. Joinvile-SC: UNIVILLE, 2003.

SARAIVA, Terezinha. Avaliação: uma abordagem ampla. Folha Dirigida, 31/03/2005. Rio de Janeiro. 2005. 


\section{Como citar este artigo:}

BOTH, Ivo José et al. Tecnologias de informação e comunicação em trabalhos de conclusão de curso lato sensu: uma positiva parceria. Revista Ibero-Americana de Estudos em Educação, Araraquara, v. 11, n. 4, p. 1943-1959, 2016. Disponível em: <http://dx.doi.org/10.21723/riaee.v11.n4.8963>. E-ISSN: 1982-5587.

Submetido em: junho/2014

Aprovação final em: outubro/2016 